\title{
Treatment of a Class-II subdivision in an Indian teenager
}

\author{
M. Givelet ${ }^{1}$, O. Sorel ${ }^{2}$ \\ 1 Qualified Specialist in Dental and Facial Orthopedics, Assistant at University Hospital, UFR \\ d'odontologie Rennes \\ 2 University Professor, Hospital Practitioner, Head of Orthodontics, Odontology Department in \\ Rennes
}

We often describe the origin of Homo sapiens as: "Out of Africa," which highlights the fact that all modern humans recently $(200,000-300,000$ years ago) originated from Africa. Modern man progressively conquered the world by traveling further and further away from this continent. Homo sapiens first appeared in Europe approximately 40,000 years ago: These humans are referred to as Cro-Magnon men. We would, therefore, be the result of a regional evolution of their descendants.

In the twentieth century, the development in transport greatly shrank the distances between regions on the planet. Modern humans can move faster and farther. In clinical orthodontics, patients with a very diverse geographical background can be encountered. Orthodontists are on difficult ground in this setting where patients must be treated on the basis of their ethnic backgrounds, and yet orthodontic concerns being distorted by racist undertones. These differences in ethnicities affect dental structures and the face, particularly from a cephalic point of view. Using the results of only North American cephalometric analyses seems inadequate. There are regional adaptations of different analyses that highlight these differences (Cephalometric norm of a Maghreb population: a study of 99 cases according to Rickett's analysis, Mémoire CECSMO, Olivier Boury, cephalometric norm for Cameroonian Bantu populations. Bacon W, Woungly R.; Rev Orthop Dento Faciale 1979;13(3):257-63). Thus, a pertinent question arises: Is it so important to try and seek out a standard, and should the standard be universally adapted? In orthodontics, in order to fit the norm, it is

Address for correspondence:

Olivier Sorel - CHU de Rennes - 2, rue Henri Le

Guilloux - 35000 Rennes,

E-mail: sorelolivier@wanadoo.fr

Article received: 31-10-2014. Accepted for publication: 30-11-2014.

This is an Open Access article distributed under the terms of the Creative Commons Attribution License (http://creativecommons.org/licenses/by/4.0), which permits unrestricted use, distribution, and reproduction in any medium, provided the original work is properly cited. 
common for healthy teeth to be extracted in order to make the individual conform to the standards of a cephalometric analysis (Julien Philippe, Orthod Fr 2009; 80:387-390).

\section{CLINICAL EXAMINATION}

\section{Medical History-General Examination}

Fritzen, aged 11 and 4 months, consulted the orthodontic clinic at the Centre de Soins Dentaires du CHU de Rennes [CHU Dental Care Center in Rennes] for the first time in February 2009. He was school-going student in the sixth grade. He was a shy but happy boy. He had an Indian background. He was willing to undergo orthodontic treatment because of a "crooked front tooth". He had no health problems and no apparent physical or postural anomalies.
The clinical case that we are presenting today attempts to illustrate this necessary individualization of our treatment objectives and their clinical application.

\section{Extraoral examination (Fig. 1)}

\section{Frontal extraoral examination}

Fritzen had a rather square and harmonious face. He had a score of 95 on Kollman's facial index: euryprosope type. The median line was not rectilinear: the chin was slightly deflected to the right. His face was slightly more developed on the right side. The ophriac, bipupillary, and commissural lines converged to the right. The lower part of the face was parallel to the upper part. The cheekbones were normal, and the ears protruded slightly. The intercanthal distance was equal to the palpebral
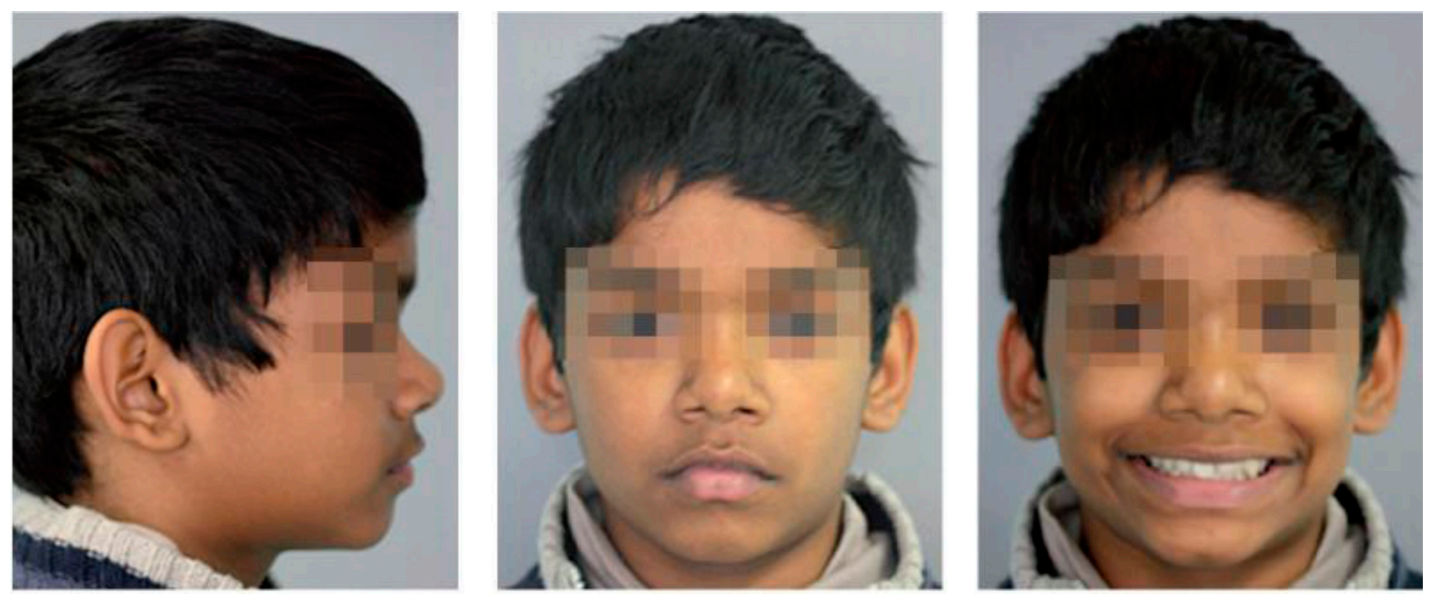

Figure 1 
fissure and the palpebral fissures were horizontal. The nasal saddle was quite thin, the nostrils were large, the nose was compressed, and the nasal alae were tense. The lower lip was thick. There was bilabial contact at rest. The lip-foramen furrow was quite marked and high.

\section{Profile extraoral examination}

The general profile is slightly convex, almost rectilinear. The subnasal profile was convex and cisfrontal. The forehead was bulging, the nasal saddle was very marked, and the nasal edge was concave. The nose was short with a nasal threshold facing upward and forward. The nasolabial angle was normal $\left(90^{\circ}\right)$. The lips were thick, both of which outcrop the esthetic line of Ricketts. The lower lip was slightly hemmed. There was bilabial contact at rest. The lip-foramen furrow is quite marked and high.

The chin was slightly indented in relation to the forehead. The distance between the neck and chin was quite short.

\section{Smiling examination}

The smile was quite symmetrical, but not harmonious. When the patient smiled, the large arches were visible.

The smile line was at the $1 / 3$ cervical level of the maxillary incisors, the maxillary and mandibular teeth were visible. The lower lip was quite horizontal, the oral cleft was wide. The maxillary incisive point was slightly deflected to the left.

\section{Summary of the extraoral examination}

Fritzen had a square face, and the face was balanced, with a slightly deflected chin on the right and bilabial contact at rest.
His general profile was slightly convex and his subnasal profile was cisfrontal. His chin was a little set-back.

His smile was not very harmonious and wide.

\section{Examination of oral and facial functions and parafunctions}

His ventilation was nasal. Swallowing was slightly dysfunctional. Phonation was normal. Chewing was unilaterally alternating. The tongue had a normal volume, normal mobility, and good posture. The lips were in contact at rest. Cephalic posture was normal.

Fritzen had no parafunctions.

Temporomandibular joints did not show signs of alteration. There was no audible snap or click, nor

muscle pain. The opening and closing pathways of the mouth were rectilinear.

\section{Intraoral examination (Fig. 2)}

\section{General examination}

Fritzen maintains proper hygiene. He does not have cavities or anything that requires immediate attention. The attached gingiva was present in sufficient thickness and height except at the lower incisors level, where they fell short. The periodontium was healthy. There were no longer any temporary teeth on the arch. The second molars were developing. His dental age corresponds to his actual age. Fritzen was in the young adult teeth formation phase according to Demogé.

\section{Interarch examination}

The general shape of the maxillary arch was parabolic and asymmetrical. Sector 2 was in a relatively mesial 

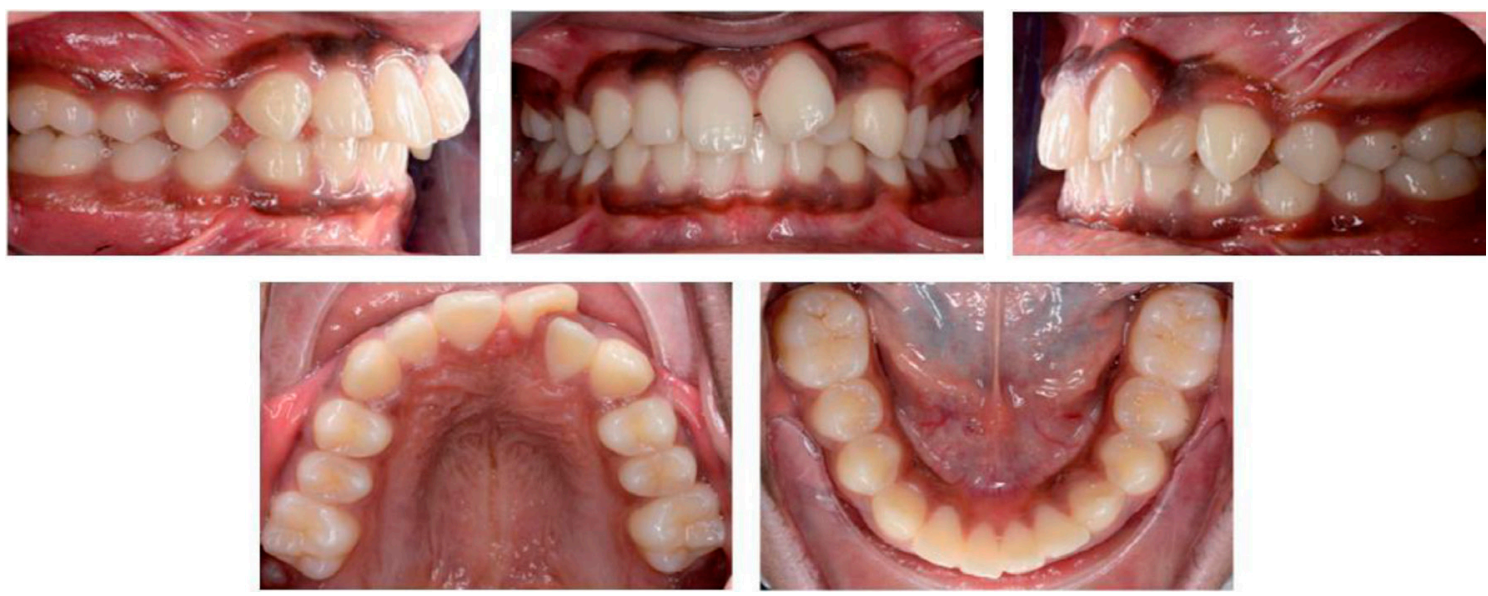

Figure 2

position and did not have the same curvature as sector 1. Wilson's curve was accentuated to the right and left. The roof of the mouth was wide.

It is worth noting the malpositions on teeth 21, 22, 23, 16, and 26.

The general shape of the mandibular arch was elliptical and symmetrical. The arrow on the Spee curve is $2 \mathrm{~mm}$ to the right and left. Note the malpositions on teeth $33,34,41$, and 42.

The maxillofacial occlusion ratios showed the following findings:

- Anterior: an incisive overhang of 3 mm-mildly increased;

- On the right: the mesial-vestibular furrow of the first mandibular molar was distorted by $2 \mathrm{~mm}$ compared to the mesial-vestibular cusp of the first maxillary molar. There are therefore Angle Class-II ratios;

- On the left: the mesial-vestibular furrow of the first mandibular molar was distorted by $1 \mathrm{~mm}$ compared to the mesial-vestibular cusp of the first maxillary molar. Thus, there were Angle Class-II ratios;
- Transverse direction

- anterior: The cross-incisive points do not coincide $(1.5 \mathrm{~mm})$. There was a deviation from the maxillary incisive point by $1.5 \mathrm{~mm}$ to the left;

- lateral: Left and right, overhang was normal;

- Vertical direction

- anterior: the overlap at the level of tooth 11 was $3 \mathrm{~mm}, 2 \mathrm{~mm}$ at the level of teeth 12, 21, and 22;

- lateral: normal overlap except at the level of tooth 23 (4 mm).

\section{Dynamic occlusion ratios show:}

- the centered relationship occlusion was different from that of maximal intercuspation. The first contact in centered relationship was between 16 and 46 and resulted in a $1 \mathrm{~mm}$ forward sliding;

- the incisal guide was made with 11 compared to 41 and 42;

- on the right lateral side, contact was made between 14 and 44 . On the left, there was a canine function. 


\section{Summary of the intraoral examination}

Fritzen was in the phase when young adult teeth develop, with an Angle Class-II, maxillary incisor malpositions, mainly with maxillary molar rotations, a deviation from the maxillary incisive point by $1 \mathrm{~mm}$ to the left. There was a $1 \mathrm{~mm}$ forward sliding.

\section{ADDITIONAL EXAMINATIONS}

\section{Molds (Fig. 3)}

\section{The X-rays}

\section{Orthopantomogram (Fig. 4)}

The X-ray was performed on March 5, 2010. The condyles seem morphologically normal. The maxillary sinuses did not show any pathological signs. The bone-supporting tissue of the teeth did not exhibit any pathological signs either. All permanent teeth were visible. The roots of the third maxillary and mandibular molars were visible, the crowns were still developing.

Tooth 21 has an important coronovestibular dilaceration.

\section{Frontal Teleradiography (Fig. 5)}

The cervical spine was not in line with the skull because of the bad positioning of Fritzen in the cephalometer. The relative craniofacial symmetry was noted with a slight right predominance.

The maxillary incisive point is deflected by $1.5 \mathrm{~mm}$ to the left.

\section{Profile teleradiography (Fig. 6)}

The characteristics of the profiled soft tissues were found on the profile teleradiography: a slightly convex profile, a bulging forehead, a very marked nasal saddle, a marked lip-foramen furrow. and a slightly set-back chin. The lips were in occlusion. The skull was well developed. The aero-pharyngeal corridor seems well developed on the image. The gonial angle
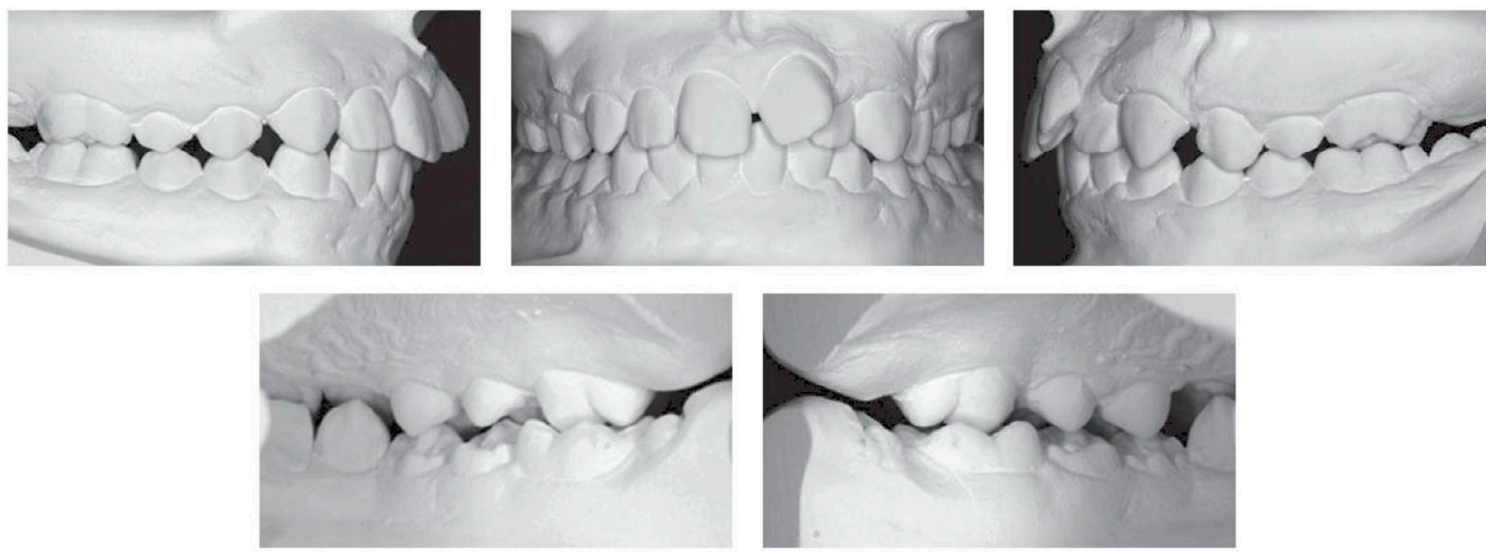

Figure 3 


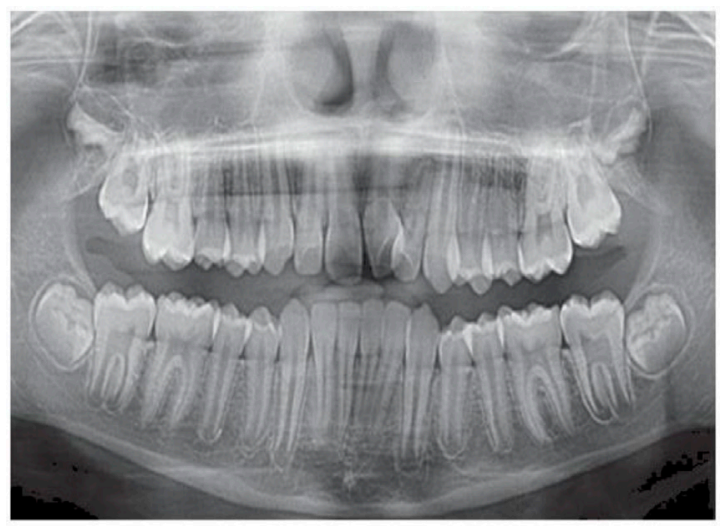

Figure 4

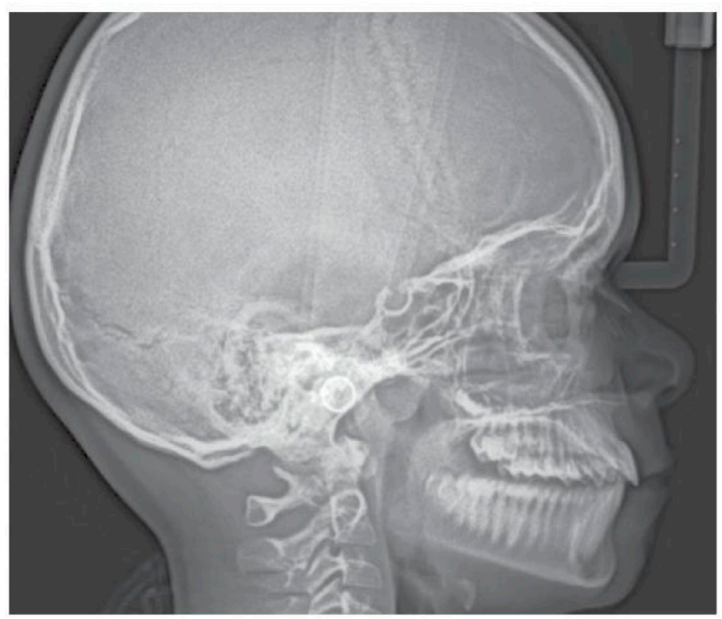

Figure 6

was located a little above the base of the axis tooth. The mandibular angle was fairly closed $\left(121^{\circ}\right)$. There was a slight sagittal splitting of the mandibular branch. The body of the mandible was quite large but the mandibular branch was very short. The body of the hyoid bone is located at the C3-C4 level. The angle of skull base was open $\left(134^{\circ}\right)$ and the structural signs of Björk were mostly those of a posterior rotation. The angle between $\mathrm{SN}$ and the Frankfurt plane was in the standard deviation $\left(9^{\circ}\right)$.

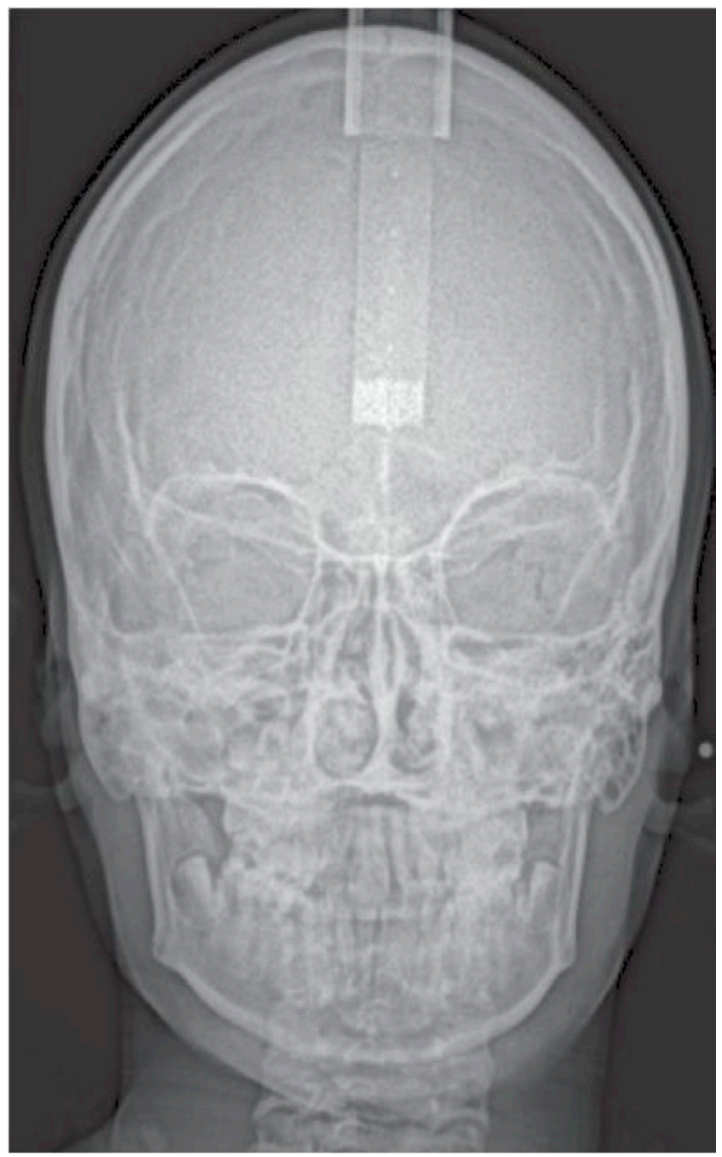

Figure 5

\section{Steiner's Cephalometric Analysis (Table. 1)}

At the skeletal level, the very decreased GoGn-SN angle indicated a hypodivergence. The ANB angle of $2^{\circ}$ and the AoBo distance of $0 \mathrm{~mm}$ indicated a Ballard skeletal Class I. The dental measurements showed a slight upper proalveolia. The distances between the lips and the esthetic line of Steiner were slightly increased and therefore indicated a slight biprochelia. 
The upper proalveolia and the biprochelia were related and are because of Fritzen's Indian background.

The conclusions of the MDD analysis according to Steiner's criteria gave us an index of $-6 \mathrm{~mm}$. The interesting part of this analysis was the discussion of this index. We then amended the project to a 1-mm lingual repositioning by advocating a vestibular advance of $1 \mathrm{~mm}$. The differential causes the index fell to $-2 \mathrm{~mm}$, which we expected to succeed without flattening the Spee curve (Fig. 7). We planned a correction of the Angle Class-II ratio with a spring-loaded molar distortion (Distal Active Concept-DAC) mechanism, which in this case was hypodivergent and was particularly well indicated. Moreover, these mechanics made it possible to manage the distalization asymmetrically.

Table /

\begin{tabular}{|c|c|c|c|c|c|}
\hline \multicolumn{2}{|c|}{ Skeletal } & Ideal & $10 / 03$ & $11 / 01$ & $12 / 03$ \\
\hline \multirow{2}{*}{$\begin{array}{c}\text { Vertical } \\
\text { direction }\end{array}$} & GoGn-SN $\left(^{\circ}\right)$ & 32 & $\mathbf{2 4}$ & $\mathbf{2 4}$ & $\mathbf{2 2}$ \\
\cline { 2 - 6 } & O-SN $\left(^{\circ}\right)$ & 14 & 14 & 16 & 15 \\
\hline
\end{tabular}

\begin{tabular}{|c|c|c|c|c|c|}
\hline \multicolumn{2}{|c|}{ Skeletal } & Ideal & $03 / 10$ & $01 / 11$ & $03 / 12$ \\
\hline $\begin{array}{c}\text { Sagittal } \\
\text { direction }\end{array}$ & SNA $\left(^{\circ}\right)$ & 82 & 82 & 81 & 82 \\
\hline \multirow{5}{*}{} & SNB $\left(^{\circ}\right)$ & 80 & 80 & 80 & 81 \\
\cline { 2 - 6 } & SND $\left(^{\circ}\right)$ & 76 & 77 & 77 & 77 \\
\cline { 2 - 6 } & ANB $\left(^{\circ}\right)$ & 2 & 1 & 1 & 1 \\
\cline { 2 - 6 } & $\begin{array}{c}\text { AoBo } \\
(\mathrm{mm})\end{array}$ & -1 & 0 & -3 & -3 \\
\cline { 2 - 6 } & $\mathrm{SE}(\mathrm{mm})$ & 22 & 21 & 23 & 23 \\
\cline { 2 - 6 } & $\mathrm{SL}(\mathrm{mm})$ & 51 & 49 & 50 & 51 \\
\hline
\end{tabular}

\begin{tabular}{|c|c|c|c|c|}
\hline Dental & Ideal & $10 / 03$ & $11 / 01$ & $12 / 03$ \\
\hline I-NA (mm) & 4 & $\mathbf{6}$ & $\mathbf{8}$ & $\mathbf{7}$ \\
\hline I-NA $\left(^{\circ}\right)$ & 22 & $\mathbf{2 6}$ & $\mathbf{3 7}$ & $\mathbf{3 2}$ \\
\hline I-NB $(\mathrm{mm})$ & 4 & 4 & 5 & 5 \\
\hline I-NB $\left(^{\circ}\right)$ & 25 & 26 & $\mathbf{3 5}$ & $\mathbf{3 3}$ \\
\hline I-I ( $\left.{ }^{\circ}\right)$ & 131 & $\mathbf{1 2 7}$ & $\mathbf{1 0 2}$ & $\mathbf{1 1 4}$ \\
\hline Pog-NB (mm) & - & 1 & 1 & 1 \\
\hline $\begin{array}{c}\text { I-NB }- \text { Pog- } \\
\text { NB (mm) }\end{array}$ & - & 3 & 4 & 4 \\
\hline
\end{tabular}

\begin{tabular}{|c|c|c|c|c|}
\hline Aesthetic & Ideal & $03 / 10$ & $01 / 11$ & $03 / 12$ \\
\hline Upper Lip/Line & $\mathbf{0}$ & $\mathbf{2}$ & $\mathbf{2}$ & $\mathbf{2}$ \\
\hline Lower Lip/Line & $\mathbf{0}$ & $\mathbf{3}$ & $\mathbf{3}$ & $\mathbf{4}$ \\
\hline
\end{tabular}

\section{Steiner Chevrons}

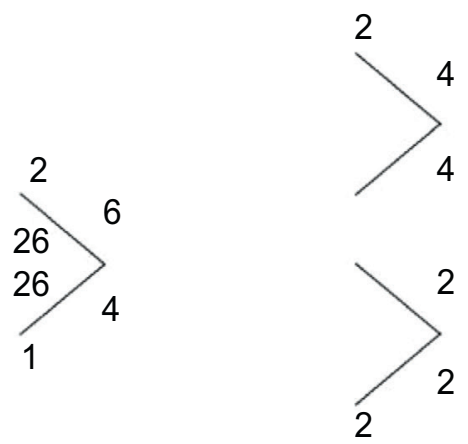

Problem
Solution 


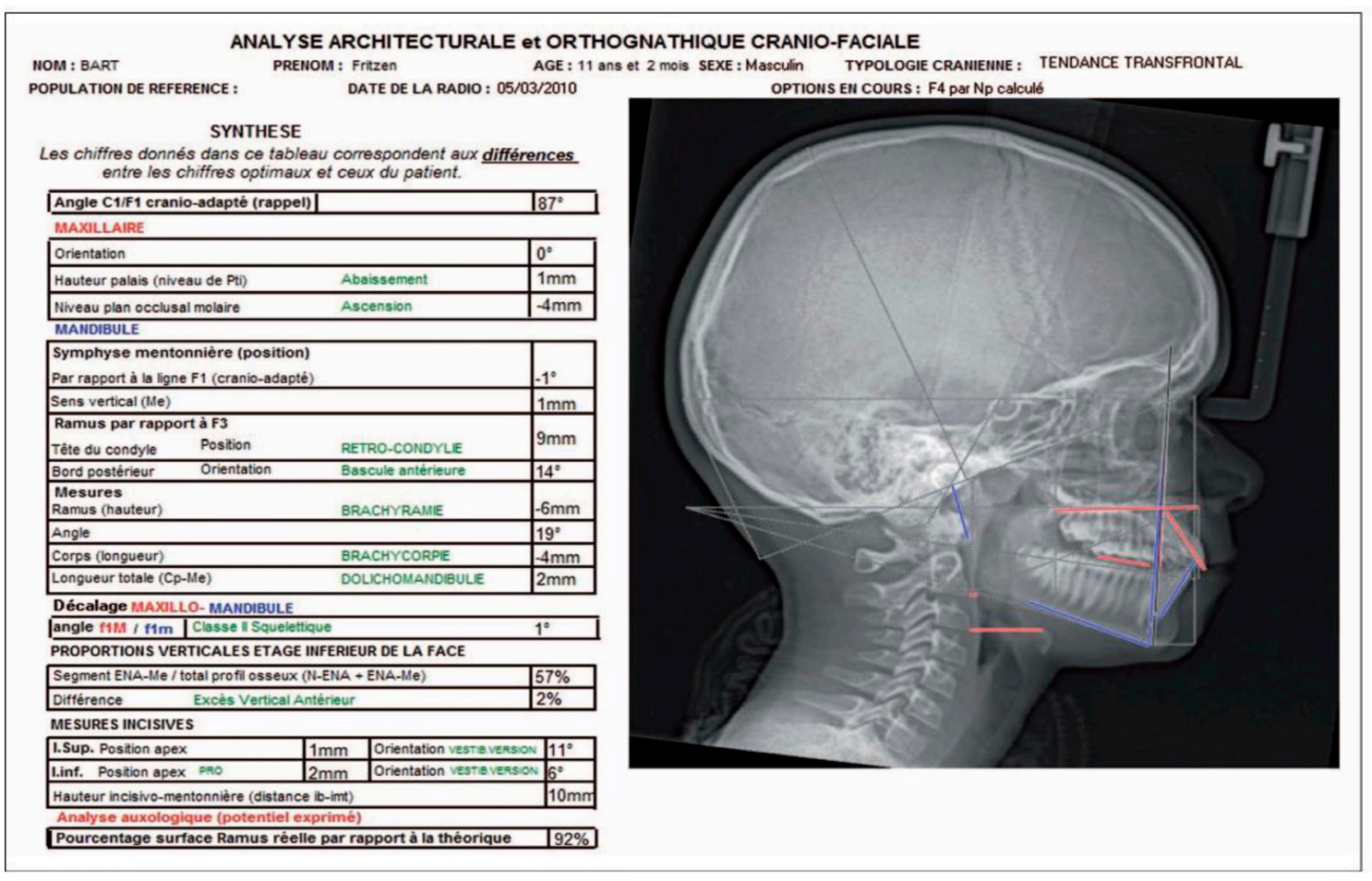

Figure 8

\section{Delair analysis (Fig. 8)}

We found it interesting to use this analysis to assess the balance of craniofacial architecture and to verify how it behaves in a person of non-Caucasian ethnicity.

\section{Results of the Delaire analysis}

The maxillae were relatively well positioned. At the mandibular level, the position of the chin was correct.

The condyle was placed a little too far back (retrocondylism) and was facing forward. The mandibular branch was short with brachyramia. Overall, we had a slightly elongated mandible).

Delaire analysis shows a skeletal Class I. There was a slight anterior vertical excess.

At the dental level, the maxillary incisor had an increased coronovestibular inclination and the lower incisor had an increased coronovestibular inclination.

The results were in agreement with Steiner's in this case.

\section{TREATMENT PLAN}

\section{Objectives}

The objectives were to correct the Class-II alveolodental ratios, correct the incisal overhang, and correct the incisive malpositions to restore a stable occlusion that favored function and esthetic balance. 


\section{The methods}

Correction of rotations of 16 and 26 with ATP. Multi-attachment of maxilla and mandibula:

- did not glue the maxillary premolars at the beginning;

- Alignment, leveling;

\section{PROGNOSIS}

Fritzen was highly motivated and followed the guidelines rigorously, therefore the prognosis was very good. The coronoradicular dilaceration of 21 did not allow an adequate root axis.

Advancing the lower incisor made it possible to envisage the conservative
- DAC placement- distalization of the maxillary molars;

- correction of the maxillary interincisal point;

- occlusal finishes.

Restraints: wire glued to lower incisors and canines, and wire glued wire or maxillary gutter.

treatment, which requires a control of the mechanics and better efficiency in order to control the position of the incisor. Otherwise an excessive version will endanger the periodontal resistance exposing it to the recession.

\section{TREATMENT STAGES}

\section{Leveling alignment stage (from 21.05.2010 to 12.11 .2010 )}

Appointment 1: ATP installation on 16 and 26 (correction of disto-vestibula rotations) of the mandibular multi-attachment with a Niti.012 arch (Fig. 9).

Appointment 2: Glue from 13 to 23 with arc Niti.014 without support of 22. Mandibular Niti.014 Arch.
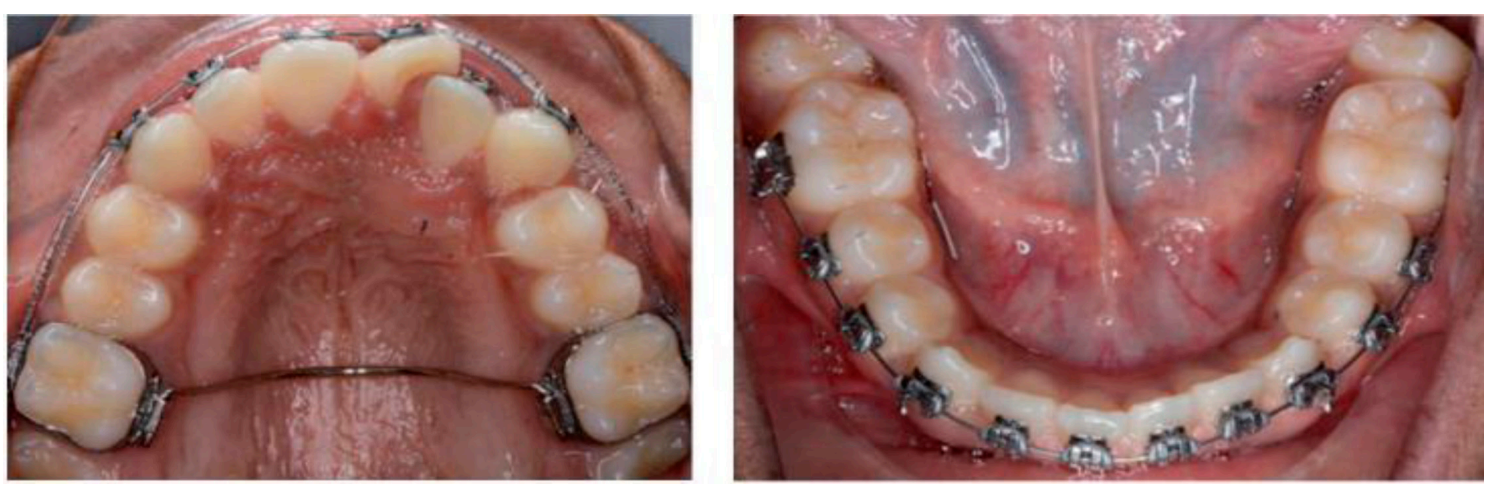

Figure 9 
Appointment 3: ATP removal (corrected rotations) and Niti.016 arch with support of 22.

Appointment 4: Maxillary: Niti.018 arch Mandible: Niti. 016 arch

Appointment 5: Maxillary: Niti $020 \times 020$ arch Mandible: Niti $020 \times$ 020 arch.

\section{Molar distalization stage (from 12.11 .2010 to 15.04 .2011 )}

Appointment 6: Maxillary: steel arch. $019 \times 025$ with $\mathrm{J}$-bracket welded into the distal face of 13 and 23 and titanium nickel springs compressed between the molars and the "J" Hooks. Mandible: steel arch $019 \times 025$. TIM II right and left $(6.31 \mathrm{~mm}, 120 \mathrm{~g})$ between the " J" hook and the first mandibular molar (Fig. 10).

Appointment 7: Activating the right spring by clipping it to the distal of the welded piton. TIM II $(6.31 \mathrm{~mm}, 120 \mathrm{~g})$.

Appointment 8: Revaluation with assessment (Table I). Regluing 32 (axis problem) and gluing 37 and 47 with Niti $020 \times 020$ arch .
Appointment 9: Maxillary: Gluing of 14, 15, 17, 24, 25 and 27 with Niti 020 $\times 020$ arch. Mandible:Temporomandibular Joint (TMJ) arch $021 \times 021$ with tip-back and marginal disto-vestibular rotation on 36 and 46.

\section{Finishings (from 20.05.2011 to 02.03.2012)}

Appointment 10: Maxillary: steel arch $019 \times 025$ with a reduction of 13 by chain from 13 to 16. Mandible: steel arch $019 \times$ 025 and finishing folds (Fig. 11).

Appointments 11-18: Finishings.

\section{End of Treatment (03.23.2012)}

Appointment 19: Remove the fasteners and put in place a 3-3 thread in the mandible and a Hawley plate.

Fritzen was a very willing and highly cooperative young patient.

Class-II mechanics allowed a correction of Class-Il dental ratios. However, the lower incisors underwent a parasitic vestibular version during the active period of treatment.
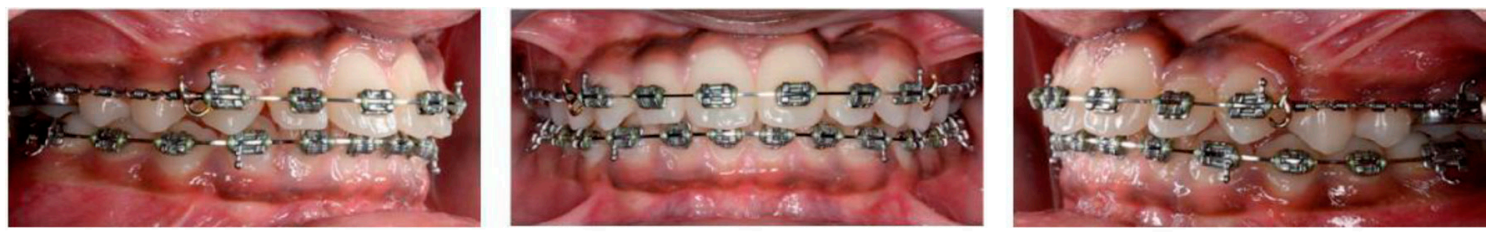

Figure 10
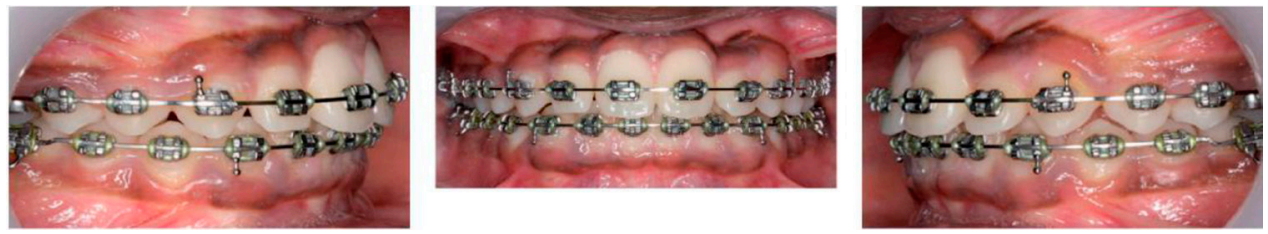

Figure 11 
Mandibular development was favorable. Was it the natural development of the patient or had there been an accelerated development by the DAC as presented by JJ. Aknin (study published in I'Orthodontie Française (French Orthodontics) in 2010)? This growth had a favorable influence on the lower incisor.

\section{END OF TREATMENT ASSESSMENT}

\section{Extraoral examination (Fig. 12)}

\section{Frontal}

There was little change. The face was longer, the small nasal and atrial asymmetries were still present. A small double chin had appeared. The gingiva was present in sufficient thickness and height except at the level of the lower incisors where the height was low. The periodontium was healthy despite mild gingival hyperplasia.

\section{Profile}

The lower lip and the chin had advanced slightly.

\section{The Smile}

The smile had become harmonious. The maxillary interincisal point had been recentered. All teeth now fitted in the oral cleft.

\section{Intraoral examination}

\section{Static examination of the occlusion}

(Fig. 13)

Sagittal: Right, Class-I molar (the mesiovestibular cuspid of the first maxillary molar was opposite to the vestibular furrow of the first mandibular molar) and Class-I canine. Left, Class-I molar and Class-I canine. The incisal overhang measured $2 \mathrm{~mm}$.

Transverse direction: cross-incisive points coincide. The lateral overhangs were correct.

Vertical direction: The incisive overlap was $2 \mathrm{~mm}$.
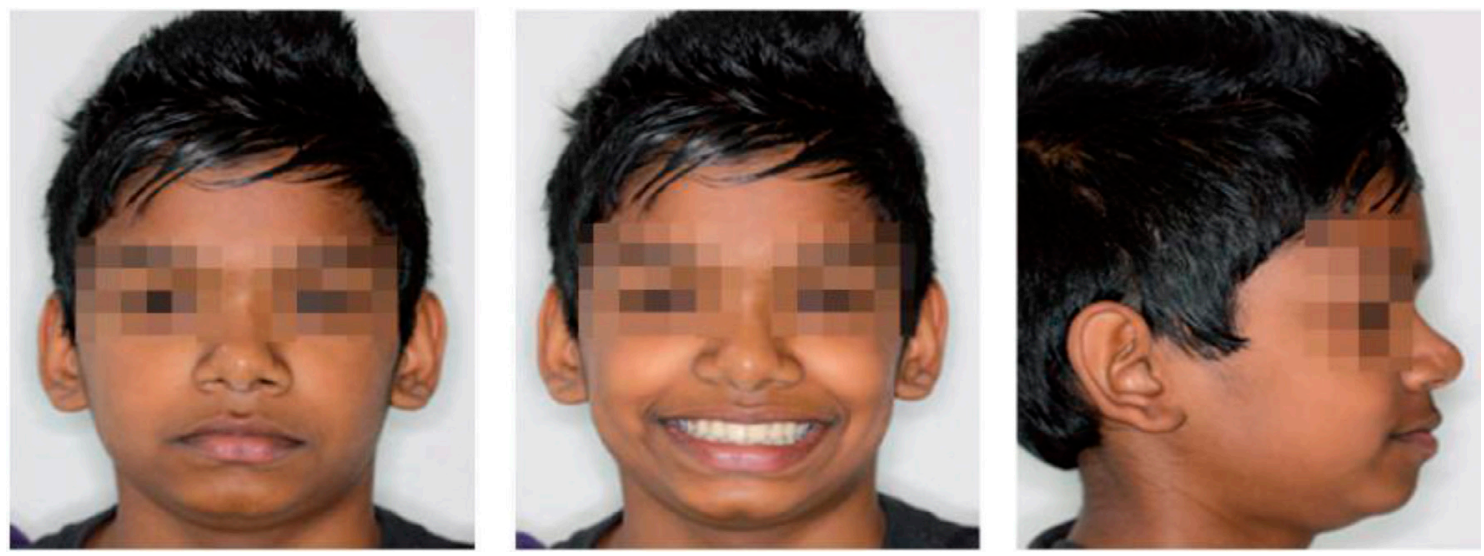

Figure 12 

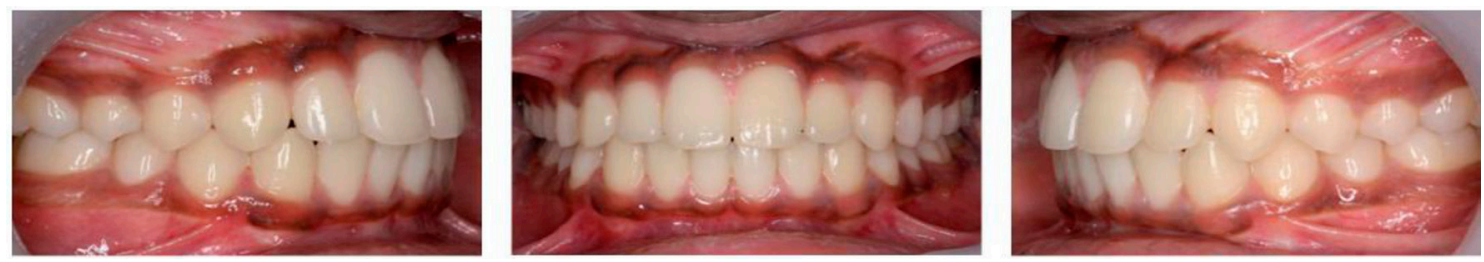

Figure 13

\section{Maximum Intercuspidal Occlusion}

(Fig. 14)

The maximum intercuspidal occlusion ( $\mathrm{MIO}$ ) correlated with the central relationship occlusion (CRO).

The occlusal contacts were well distributed (cuspal pits or ridges). There was no contact on $27 / 37$ or on 11 .

\section{Dynamic Occlusion Examination} (Fig. 15)

Propulsion: the incisal guide led to posterior deocclusion without interference.

Left Diduction: canine and lateral incisor function at the end of the treatment.

We did not observe any interference.

Right Diduction: canine and lateral incisor function at the end of the treatment.

We did not observe any interference.

\section{The X-rays}

\section{Orthopantomogram (Fig. 16)}

This examination did not show any evidence of root resorption.

The roots of the third maxillary and mandibular molars were visible, the crowns had almost formed.

The coronoradicular dilaceration was still visible on the distal root of 21 .

\section{Profile teleradiography (Fig. 17)}

The lower lip and chin seem to have advanced. The arches are Class I. The mandibular symphysis was even more bulbous.

\section{Steiner's Cephalometric Analysis (Table. 1)}

Table I includes the measures taken at the beginning of treatment, during the revaluations, as well as the end of treatment. The cephalometric revaluation reveals a small closure of the GoGn-SN angle (small anterior mandibular rotation has occurred during development). The occlusion plane was maintained: with little or no tilting. The axes of the incisors suffered from linguoversion compared to January 2011, but remained more inclined with the position chosen in the treatment plan (Fig. 18).

Lautrou cephalometric overlays

(Fig. 19): General overlay:

- general downward and forward growth;

- maxillary:

- total hourly rotation;

- slight hourly matrix rotation;

- mandible:

- slight total hourly rotation;

- slight matrix rotation; 

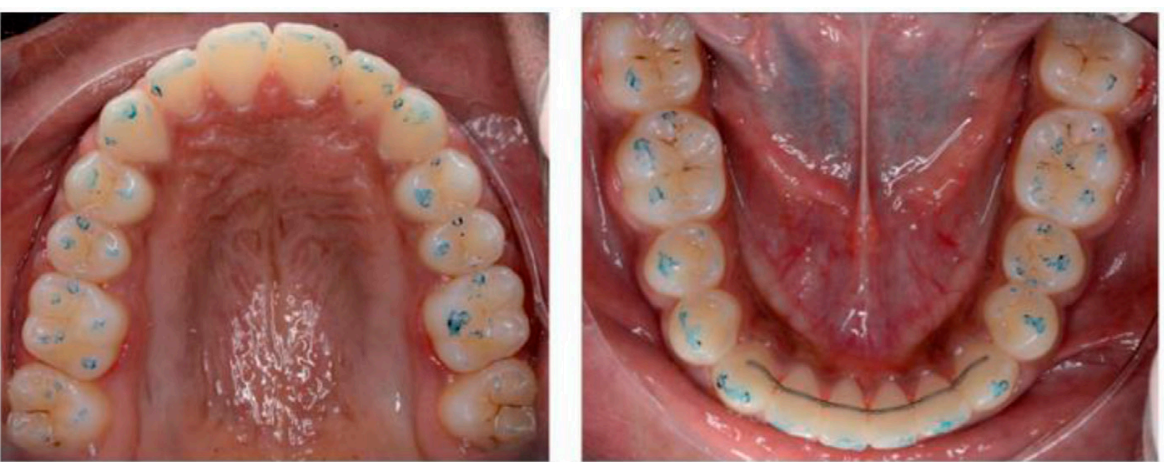

Figure 14
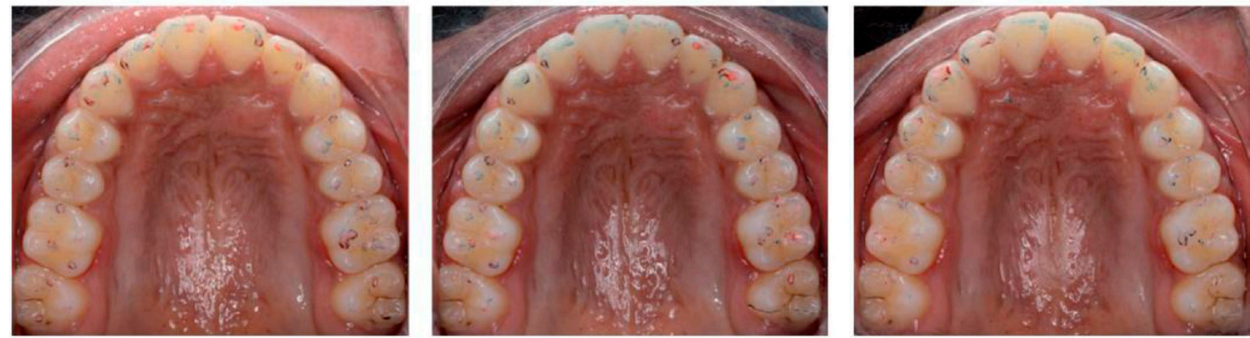

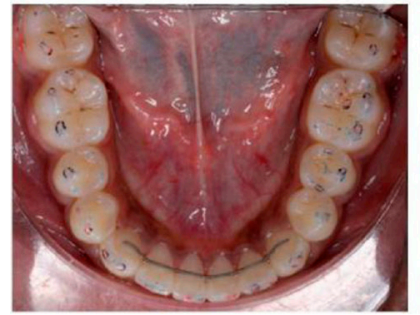

Propulsion

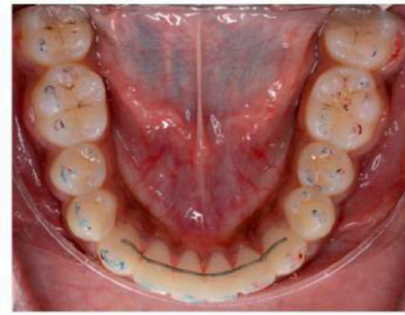

Left Diduction

Figure 15

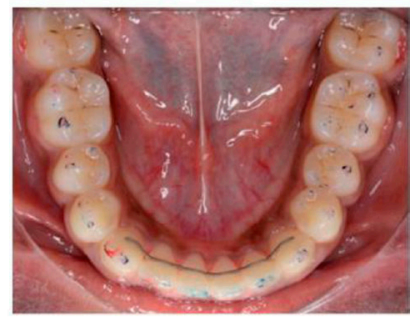

Right diduction

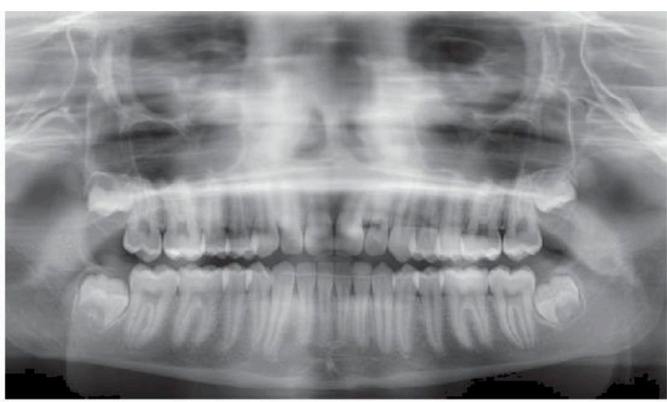

Figure 16

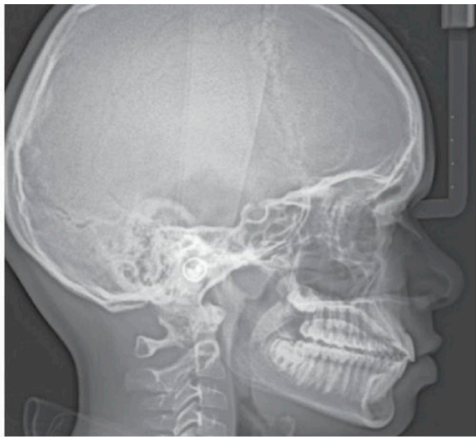

Figure 17 


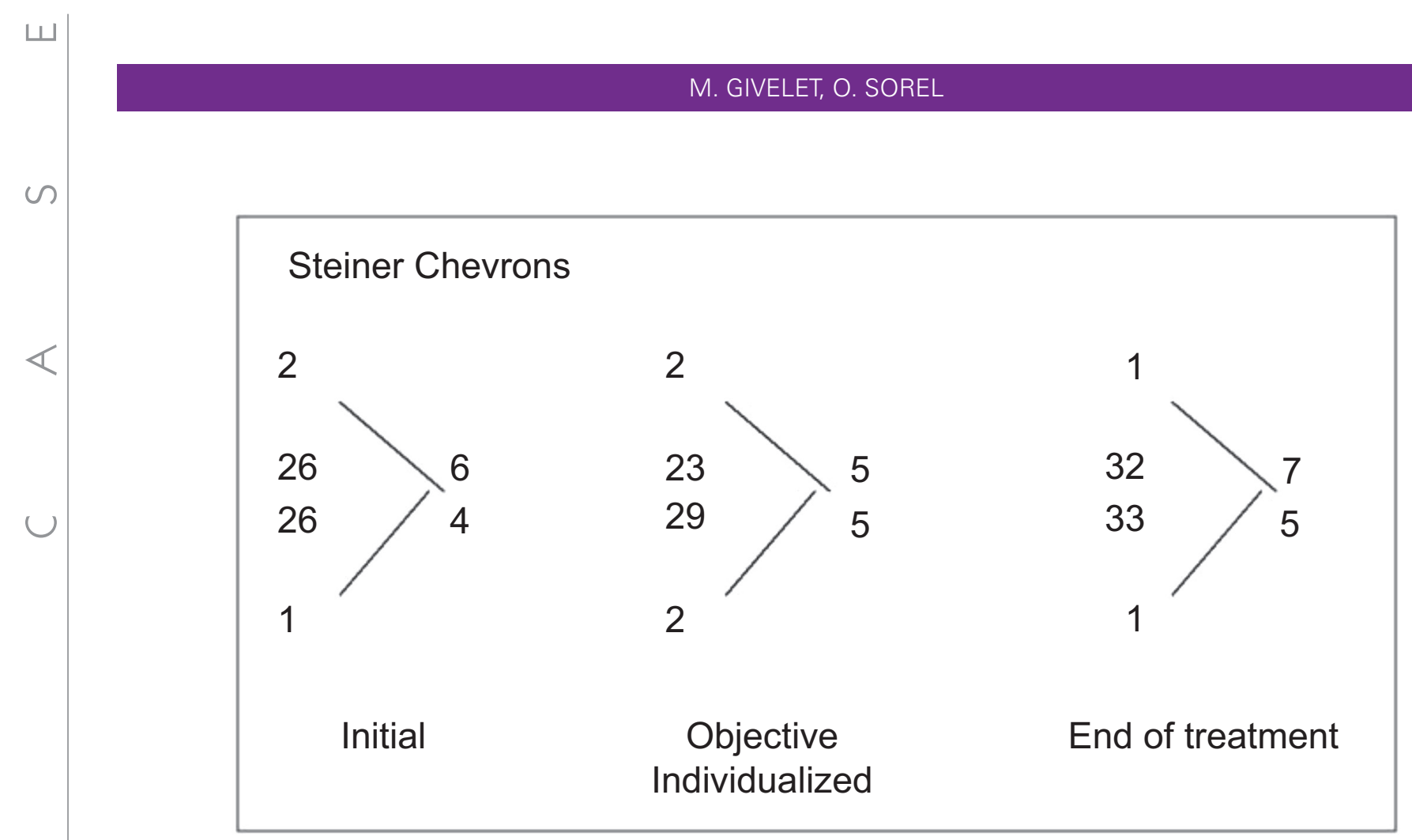

Figure 18

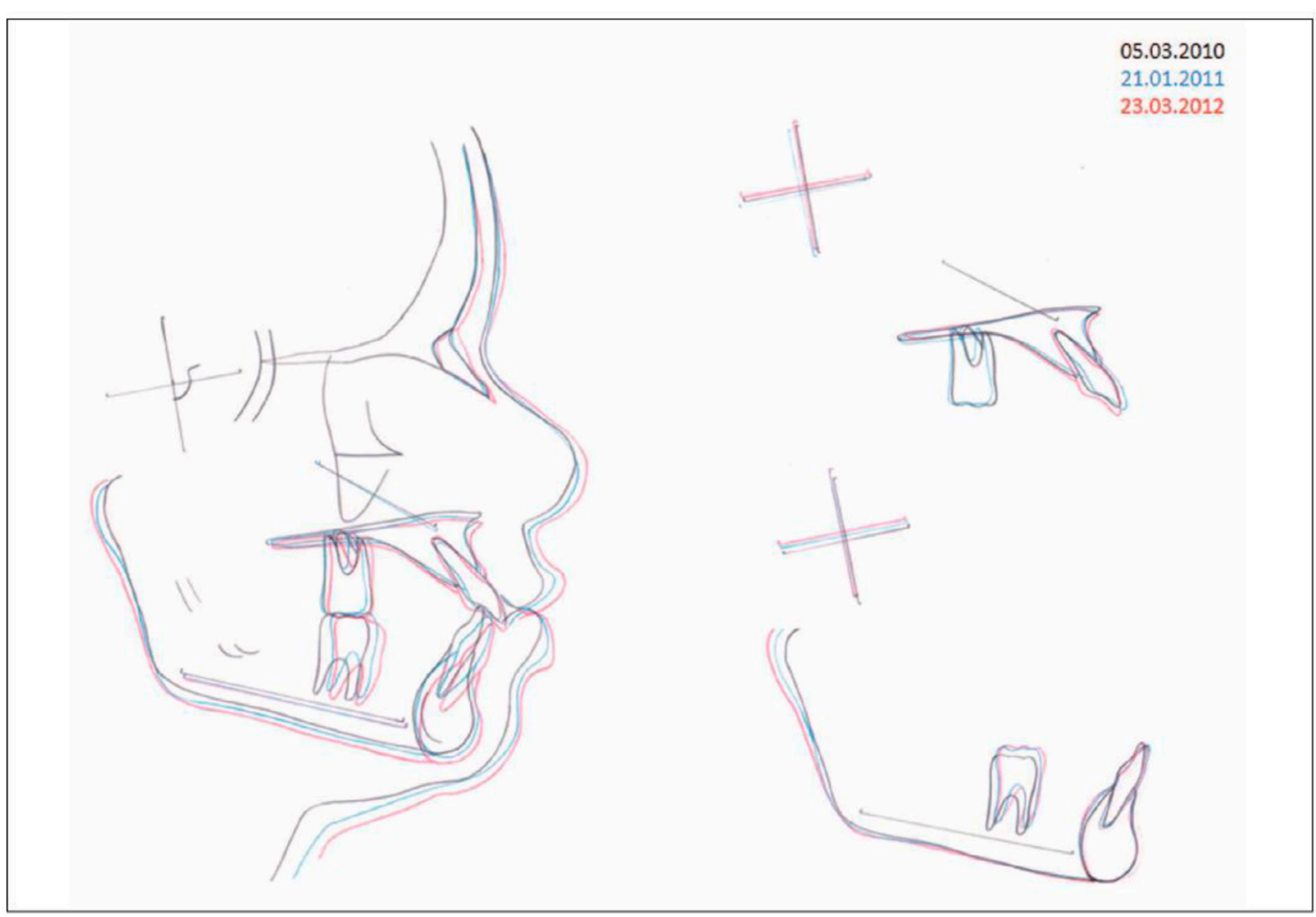

Figure 19 
- alveolodental:

- small hourly shift according to the occlusal plane.

Local overlays:

- maxillary:

- slight intra-matrix rotation;

- the incisor shows a slight case of palatoversion and the molar had not moved;

- mandible:

- slight intra-matrix counter-clockwise rotation;

- the incisor shows a slight case of linguoversion;

- the molar had not moved.
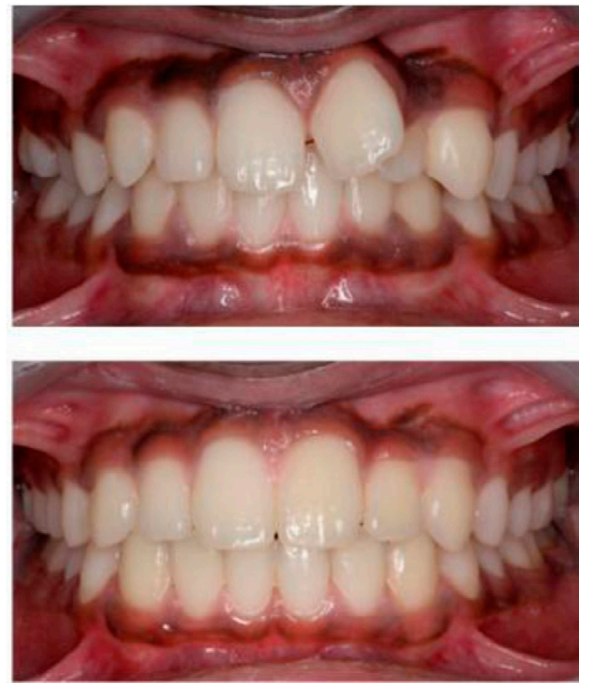

Figure 20

periodontium of the lower incisors had developed normally during the treatment without any iatrogenic effects (Fig. 20).

A support wire was laid from 33 to 43 and a nocturnal Hawley plate supported the maxillary arch.

The healthy periodontium, the morphological equilibrium of the face, and especially his smile, confirm that we made the right treatment choices.

Conflict of interest: The authors declare that they have no conflict of interest. 